\title{
Comparison of balloon angioplasty and papaverine infusion for the treatment of vasospasm following aneurysmal subarachnoid hemorrhage
}

J. Paul Elliott, M.D., David W. Newell, M.D., Derek J. Lam, Joseph M. Eskridge, M.D., Colleen M. Douville, B.A., R.V.T., Peter D. LeRoux, M.B., ChB., M.D., David H. Lewis, M.D., Marc R. Mayberg, M.D., M. Sean Grady, M.D., and H. Richard Winn, M.D.

Departments of Neurological Surgery and Radiology, University of Washington School of Medicine, Harborview Medical Center, Seattle, Washington

The authors used daily transcranial Doppler (TCD) evaluation to test the hypothesis that balloon angioplasty is superior to papaverine infusion for the treatment of proximal anterior circulation arterial vasospasm following subarachnoid hemorrhage (SAH). Between 1989 and 1995, 125 vasospastic distal internal carotid artery or proximal middle cerebral artery vessel segments were treated in 52 patients. Blood flow velocities of the involved vessels were assessed using TCD monitoring in relation to the day of treatment with balloon angioplasty or papaverine infusion. Balloon angioplasty and papavarine infusion cohorts were compared based on mean pretreatment velocity and mean posttreatment velocity at 24 and 48 hours using the one-tailed, paired-samples t-test. Balloon angioplasty alone was performed in 101 vessel segments $(81 \%)$ in 39 patients $(75 \%)$, whereas papaverine infusion alone was used in 24 vessel segments $(19 \%)$ in 13 patients $(25 \%)$. Although repeated treatment following balloon angioplasty was needed in only one vessel segment, repeated treatment following papaverine infusion was required in 10 vessel segments $(42 \%)$ in six patients because of recurrent vasospasm $(p<0.001)$. Seven vessel segments $(29 \%)$ with recurrent spasm following papaverine infusion were treated with balloon angioplasty. Although vessel segments treated with papaverine demonstrated a $20 \%$ mean decrease in blood flow velocity $(\mathrm{p}<0.009)$ on posttreatment Day 1 , velocities were not significantly lower than pretreatment levels by posttreatment Day $2(\mathrm{p}=0.133)$. Balloon angioplasty resulted in a $45 \%$ mean decrease in velocity to a normal level following treatment $(\mathrm{p}<0.001)$, which was sustained. The authors conclude that balloon angioplasty is superior to papaverine infusion for the permanent treatment of proximal anterior circulation vasospasm following aneurysmal $\mathrm{SAH}$.

Key Words * subarachnoid hemorrhage * vasospasm * transcranial Doppler ultrasound * balloon angioplasty * papaverine

Cerebral vasospasm remains a leading cause of heightened morbidity and mortality rates following aneurysmal subarachnoid hemorrhage (SAH)[20] despite the apparent benefit of hypervolemic/hypertensive treatment[43] and calcium channel-blocking agents.[42] The development of 
noninvasive transcranial Doppler (TCD) evaluation of the cerebovasculature has greatly facilitated the early diagnosis of vasospasm and the routine monitoring of cerebral arterial blood velocity following treatment.[39] Successful resolution of medically refractory angiographically demonstrated vasospasm, with concomitant reversal of delayed neurological deficit, has been observed after balloon angioplasty treatment. $[9,15,36]$ More recently, papaverine infusion has been used, with varying results in a small number of patients.[18,19] This study retrospectively compared balloon angioplasty with papaverine infusion for their efficacy in permanently reversing proximal anterior circulation vasospasm following SAH as measured by TCD monitoring.

\section{CLINICAL MATERIAL AND METHODS}

\section{Patient Population, Diagnosis, and Initial Management}

A retrospective review has been made of the medical records of all patients with the diagnosis of ruptured cerebral aneurysm who were admitted to Harborview Medical Center at the University of Washington between September 1989 and July 1995. On admission, SAH caused by a ruptured aneurysm was confirmed by computerized tomography (CT) scanning or by lumbar puncture. Aneurysm location was assessed using four-vessel angiography or, in the case of moribund patients, by infusion CT scanning. $[23,38]$ All patients admitted during this time period were considered surgical candidates and treated by a standardized protocol. Following preoperative resuscitation, patients were treated with early surgery, aggressive management of intracranial pressure and vasospasm, and intensive perioperative care, as previously described.[24-26] Routine intracranial pressure and invasive hemodynamic monitoring and frequent CT scans of the head supplemented clinical evaluation. Phenytoin and nimodipine were routinely administered to achieve therapeutic levels. Volume expansion was initiated prophylactically.

\section{Transcranial Doppler Evaluation}

A baseline admission and repeated (usually daily) perioperative TCD examinations were performed in all patients by experienced examiners using standard technique.[11] The highest velocity in each vessel segment was recorded. Distal internal carotid artery (ICA) velocity was measured by transorbital or transtemporal TCD sonography and middle cerebral artery (MCA) velocity was measured by transtemporal TCD. Each TCD examination included velocity measurements in both cervical ICAs via a submandibular approach. The quotient of the intracranial ICA or MCA velocity to the ipsilateral cervical ICA velocity (intracranial/extracranial ratio) allows for correction of systemic factors that alter volume flow.[3] The criterion for vasospasm of the distal ICA or proximal MCA was defined as a velocity greater than or equal to $120 \mathrm{~cm} / \mathrm{second}$ with an intracranial/extracranial velocity ratio greater than or equal to 3 (Table 1). Vasospasm was confirmed by angiography prior to treatment with balloon angioplasty or papaverine infusion. Transcranial Doppler sonography has the greatest accuracy for the diagnosis of vasospasm of the distal ICA and proximal MCA, and these vessel segments are the most amenable to balloon angioplasty. This study was therefore confined to assessing vasospasm in these vessel segments. Serial single-photon emission computerized tomography (SPECT) scans were used to assess the change in relative cerebral blood flow (CBF) in the affected territories in many of these patients.[28,29] 


\begin{tabular}{|c|c|c|}
\hline \multicolumn{3}{|c|}{$\begin{array}{c}\text { TABLE } 1 \\
\text { CRITER M FOR TRANSCRANML DOPPLER EVALUATION OF ICA } \\
\text { OR MCA YSOSPASM }\end{array}$} \\
\hline $\begin{array}{l}\text { Mean } \\
\text { Velocity (cmlsec) }\end{array}$ & $\begin{array}{l}\text { Irtracrariall Extracranial } \\
\text { Velocity' Rati } 0^{*}\end{array}$ & Interpretation \\
\hline $\begin{array}{l}\times 120 \\
\doteq 120 \\
=200\end{array}$ & $\begin{array}{l}x 3 \\
3-6 \\
>6\end{array}$ & $\begin{array}{l}\text { normal or nonspecific elevation } \\
\text { vasospasm } \\
\text { severe vaso spasm }\end{array}$ \\
\hline \multicolumn{3}{|c|}{$\begin{array}{l}\text { "Quotient of distal in tracranial ICA or proximal MCA welocity and the ipsilater- } \\
\text { al extracranial ICA welocity. }\end{array}$} \\
\hline
\end{tabular}

\section{Treatment of Vasospasm}

Aneuryms in all patients were obliterated prior to intraarterial treatment of vasospasm. Balloon angioplasty was used to treat refractory vasospasm in all cases presenting before 1992. Since 1992, papaverine infusion has been used alone or in conjunction with balloon angioplasty in accordance with the clinical judgment of the treating interventional neuroradiologist (J.M.E.). Following confirmatory angiography, all accessible vasospastic segments were treated. Following balloon angioplasty in the symptomatic segments, papaverine infusion was often used to treat contralateral vasospastic segments or to improve balloon access. Papaverine infusion alone was not usually used in the most severe cases. In cases in which patients were referred with unclipped aneurysms and severe, symptomatic vasospasm, balloon angioplasty and/or papaverine infusion was instituted immediately following aneurysm obliteration.[27]

\section{Balloon Angioplasty}

After the patient had been fully heparinized, a transfemoral approach was used to place an introducer catheter in the ICA. A low-pressure silicone angioplasty balloon was attached to a microcatheter of varying stiffness (Target Therapeutics Corp., San Jose, CA). With the aid of high-resolution digital fluoroscopy with digital road-mapping capabilities, the balloon was inflated and deflated in less than 5-second intervals, moving proximally to distally along the course of the spastic vessel.[8,9] Heparinization was reversed by means of protamine sulfate after a posttreatment angiogram had been obtained.

\section{Papaverine Infusion}

Intraarterial papaverine was infused by placing a microcatheter just proximal to the spastic segment or, in some cases, more proximally in the ICA. Doses of approximately $300 \mathrm{mg}$ per vessel were infused over 20 minutes to 1 hour while changes in blood pressure and intracranial hypertension were monitored.[33] Posttreatment angiography was performed to assess the effects of treatment in all cases.

\section{Comparison of Balloon Angioplasty and Papaverine Infusion}

Vasospasm of the involved distal intracranial ICA or proximal MCA was assessed in relation to the day of treatment with balloon angioplasty or papaverine infusion by using TCD monitoring of both the absolute velocity of blood flow and the intracranial/extracranial velocity ratio. Pretreatment velocity (Day 0) was compared to the velocity at 24 (postoperative Day 1) and 48 hours posttreatment (postoperative Day 2) for each vessel segment using the one-tailed, paired-samples t-test. Vessels initally treated with a combination of the two methods were excluded from this analysis. Vessels treated 
successively with papaverine infusion and then balloon angioplasty, or with repeated treatment of either, were included in the original treatment cohort until the day of the subsequent treatment. Statistical analysis was performed using a commercially available software package (SPSS 6.1; Chicago, IL).

\section{Regional Cerebral Blood Flow Assessment}

Single-photon emission 99m-HMPAO computerized tomography scans were obtained pre- and posttreatment in a subset of patients by means of methodology previously described.[28,29] The radiopharmaceutical was injected intravenously within 30 minutes of reconstitution. Between 30 minutes and several hours following injection, scanning was performed using low-energy, high-resolution collimation. Reconstructions were back-projection filtered, and attenuation correction was made using the Chang boundary method. Images were added to make contiguous slices comparable to the spatial resolution of the camera system and interpreted by a nuclear medicine physician experienced in brain SPECT imaging interpretation. The cerebellum was used as an internal reference point for comparison to the supratentorial uptake of radiopharmaceutical. The paired SPECT studies of regional (r)CBF before and after vessel segment treatment with either balloon angioplasty or papaverine infusion were interpreted together in the transverse, coronal, and sagittal planes. Changes in blood flow in the territory supplied by the treated vasospastic vessel were summarized as worsened, unchanged, or improved.

\section{RESULTS}

\section{Clinical Data}

During the study period from February 1989 to June 1995, 587 patients were surgically treated for a ruptured cerebral aneurysm. Seventy-eight patients developed medically refractory, symptomatic vasospasm. In the 52 patients initally treated by either balloon angioplasty (39 patients) or papaverine infusion alone (13 patients), a total of 125 anterior circulation distal ICA or proximal MCA vessel segments were evaluated. A combination of both modalities was used to treat 26 patients. The proximal MCA accounted for the majority of vessel segments treated in both the balloon angioplasty $(56 \%)$ and the papaverine infusion cohorts $(63 \%)$. Age, gender, SAH grade at presentation, aneurysm location, and clinical deficit associated with anterior circulation vasospasm were similar in the two treatment groups (Table 2). 
TABLE 2

CLINICAL CHARACTER ISTICS OF 52 PATIENTS TREATED WITH PAPAYER NE INFUSON OR BALLON ANGOPLASTY太

\begin{tabular}{|c|c|c|}
\hline Characteristic & $\begin{array}{l}\text { Papaverine Inf usion } \\
\text { No. of Patients [\%] }\end{array}$ & $\begin{array}{l}\text { Ball oon Angioplasty } \\
\text { No. of Patients (\%) }\end{array}$ \\
\hline $\begin{array}{l}\text { age (Grs } \mathrm{SEM} \text { ) } \\
\text { range }\end{array}$ & $\begin{array}{l}52 \pm 4 \\
27-53\end{array}$ & $\begin{array}{l}45 \pm 2 \\
22-73\end{array}$ \\
\hline \multicolumn{3}{|l|}{$\operatorname{sen}$} \\
\hline female & $9(69)$ & $25(64)$ \\
\hline male & $4(31)$ & $14(36)$ \\
\hline \multicolumn{3}{|l|}{ grade at presentation } \\
\hline I-III & $10(77)$ & $26(67)$ \\
\hline $\mid W-W$ & $3(23)$ & $13(33)$ \\
\hline \multicolumn{3}{|l|}{ aneurysm location } \\
\hline anterior circulation & $12(92)$ & 33 (85) \\
\hline posterior circulation & $1(8)$ & $6(15)$ \\
\hline \multicolumn{3}{|l|}{ clinical de ficit w/ wasospasm } \\
\hline al tered consciousness & $9(69)$ & $20(51)$ \\
\hline meakness & $1(8)$ & $6(16)$ \\
\hline combination or other & $3(23)$ & $13(33)$ \\
\hline \multicolumn{3}{|l|}{ deficit resolution } \\
\hline $\begin{array}{l}\text { Initual treatm ent } \\
\text { subsequent treatment }\end{array}$ & $\begin{array}{l}8(09) \\
8(62)\end{array}$ & $29(14)$ \\
\hline \multicolumn{3}{|l|}{$\begin{array}{l}\text { Sucsequent treatment } \\
\text { GOS rankingt }\end{array}$} \\
\hline faworatle & $8(62)$ & $26(67)$ \\
\hline unfaworable & $5(38)$ & $13(33)$ \\
\hline
\end{tabular}

\section{TCD Velocity Measurement After Treatment of Vasospasm}

Balloon Angioplasty. In 101 vessel segments in 39 patients treated with balloon angioplasty, the mean combined TCD-measured blood flow velocity in the distal ICA and proximal MCA increased from a baseline of $95 \pm 12$ to $166 \pm 9 \mathrm{~cm} / \mathrm{second}$ just before treatment. This decreased significantly to $92 \pm 4$ $\mathrm{cm} /$ second following balloon angioplasty and remained stable ( $\mathrm{p}<0.001$; Fig. 1 left). The intracranial/extracranial blood flow velocity also decreased significantly from $5 \pm 0.3$ just before treatment to $2.5 \pm 0.1 \mathrm{~cm} /$ second following treatment ( $<<0.001$; Fig. 1 right). When distal intracranial ICA segments and proximal MCA segments treated by balloon angioplasty were analyzed separately, these relationships persisted. Distal intracranial ICA flow velocity decreased from $118 \pm 77$ to $81 \pm 6$ $\mathrm{cm} /$ second $(\mathrm{p}<0.001)$ and the intracranial ICA/extracranial ICA ratio decreased from $3.5 \pm 0.3$ to $2.1 \pm$ 0.2 ( $\mathrm{p}<0.001$ ). Proximal MCA flow velocity decreased from $206 \pm 8$ to $100 \pm 5 \mathrm{~cm} / \mathrm{second}$ ( $\mathrm{p}<0.001$ ), and the proximal MCA/extracranial ICA ratio decreased from $6.1 \pm 0.4$ to $2.7 \pm 0.2(\mathrm{p}<0.001)$. 


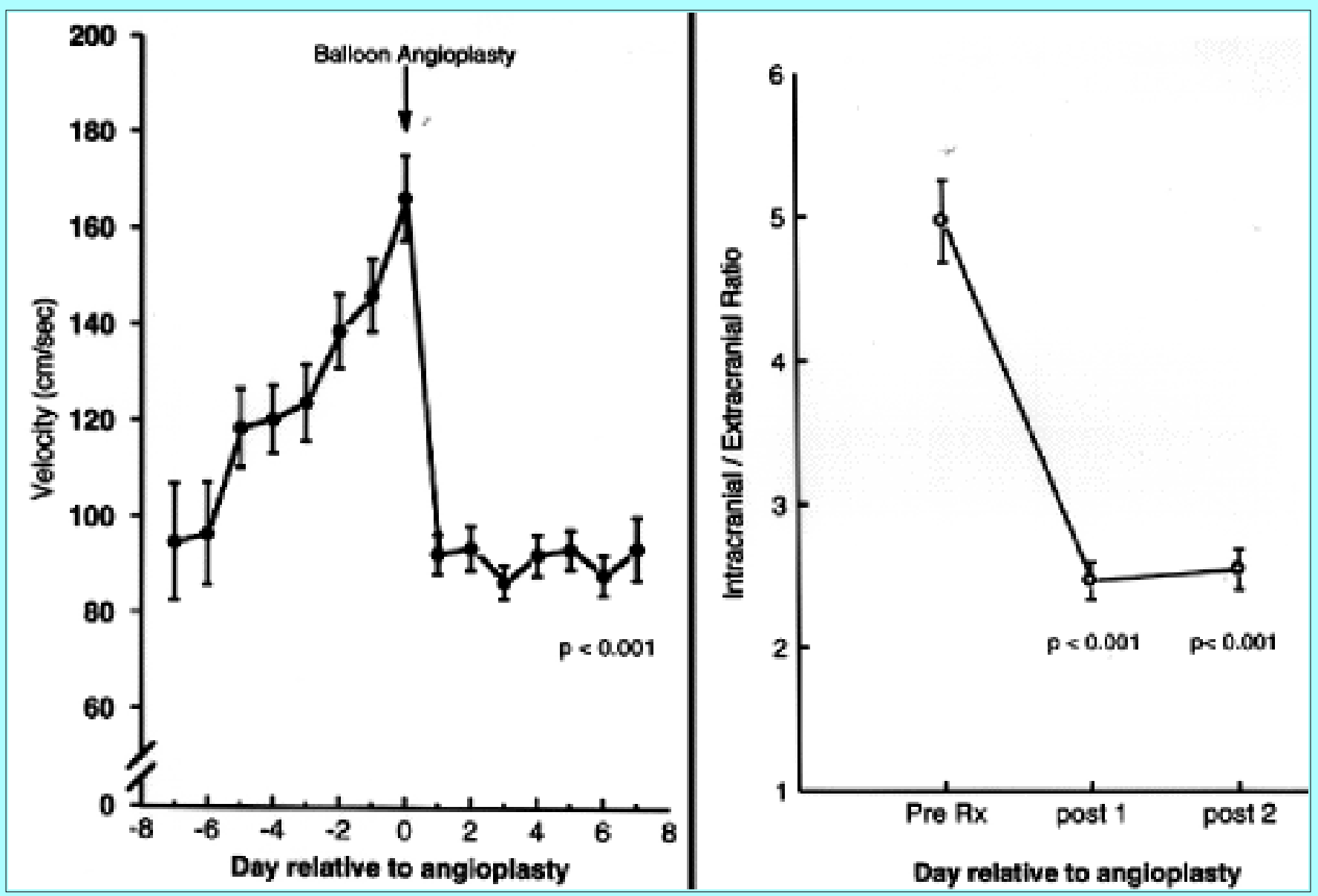

Fig. 1. Left: Graph showing the results of treatment of vasospasm with balloon angioplasty in 101 distal ICA or proximal MCA vessel segments in 39 patients that resulted in a sustained decrease of mean TCD-measured flow velocity to normal levels. Right: Graph showing the mean TCD-measured flow velocity ratio (MCA or distal intracranial ICA/extracranial ICA) in patients treated with balloon angioplasty demonstrating a sustained decrease.

Papaverine Infusion. In 24 vessel segments of 13 patients treated with papaverine infusion, the mean TCD-measured blood flow velocity was $158 \pm 8 \mathrm{~cm} / \mathrm{second}$ just before treatment, and although this value decreased significantly to $127 \pm 13 \mathrm{~cm} / \mathrm{second}$ ( $\mathrm{p}=0.008$; Fig. 2 left) on posttreatment Day 1 , the mean velocity failed to reach normal levels and increased toward pretreatment levels by posttreatment Day 2 ( $p$ $=0.133$ ). The associated intracranial/extracranial ratio decreased from $4.1 \pm 0.4$, pretreatment, to $3.7 \pm$ 0.5 on posttreatment Day 1 ( $\mathrm{p}=0.230$; Fig. 2 right) but increased above the pretreatment value by posttreatment Day $2(\mathrm{p}=0.310)$. When distal ICA segments and proximal MCA segments treated by papaverine infusion were analyzed separately, the mean distal ICA velocity and ratio failed to demonstrate a significant response at 1 or 2 days posttreatment. Although proximal MCA flow velocity decreased from $166 \pm 10 \mathrm{~cm} / \mathrm{second}$ just before papaverine treatment to $135 \pm 15 \mathrm{~cm} / \mathrm{second}$ on posttreatment Day $1(\mathrm{p}=0.018)$, it failed to reach normal levels, increasing to $140 \pm 13 \mathrm{~cm} / \mathrm{second}$ by posttreatment Day $2(\mathrm{p}=0.028)$. 


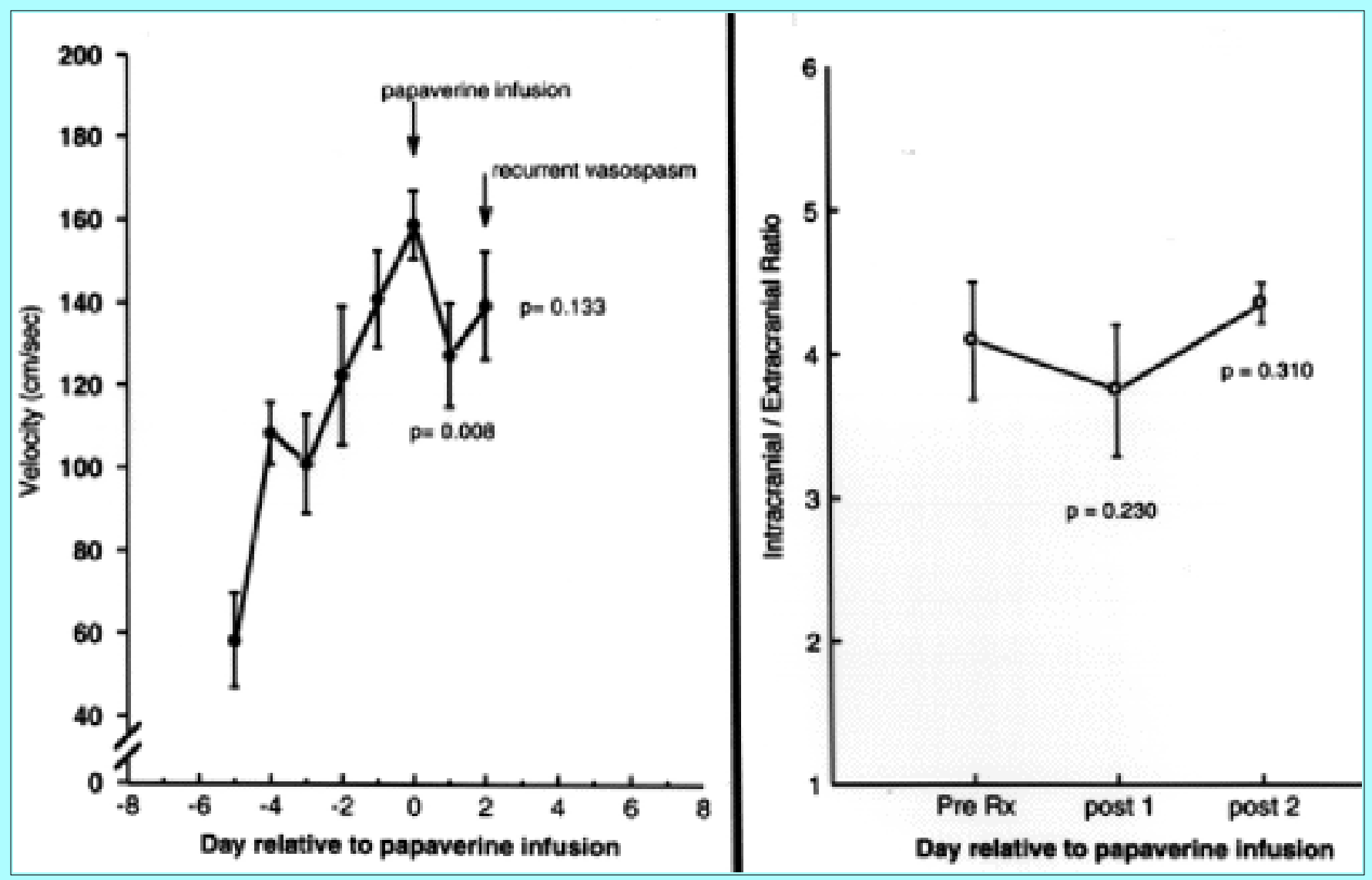

Fig. 2. Graph showing treatment results of papaverine infusion in 24 distal intracranial ICA or proximal MCA vessel segments in 13 patients that resulted in an initial transient decrease in mean velocity which failed to reach normal levels and increased toward pretreatment levels within 2 days. Right: Graph showing that the mean TCD velocity ratio (MCA or distal intracranial ICA/extracranial ICA) also decreased transiently in patients treated with papaverine infusion, returning to pretreatment levels within 2 days.

\section{Response to Treatment}

Angiographic response at the time of initial treatment was observed in all patients treated with either balloon angioplasty or papaverine infusion. However, a failure to respond clinically coupled with recurrent elevation of TCD-measured flow velocity necessitated repeated treatment for vasospasm. This occurred in patients initially treated with papaverine infusion significantly more often than in patients initially treated with balloon angioplasty ( $\mathrm{p}<0.001$, Fisher's exact test; Table 3 ). Thirteen vessel segments $(54 \%)$ in eight patients $(62 \%)$ initially treated with papaverine infusion alone required repeated treatment: six vessel segments in three patients were treated with repeated papaverine infusion; three segments in two patients with balloon angioplasty; and four segments in three patients with both modalities simultaneously (Table 3). Only one patient (3\%) initially treated with balloon angioplasty alone required retreatment. Overall, a favorable clinical outcome was achieved in 26 patients $(67 \%)$ initially treated with balloon angioplasty (Table 2). While eight patients $(62 \%)$ initially treated with papaverine infusion ultimately achieved a favorable outcome, repeated treatment with balloon angioplasty and/or papaverine infusion was necessary in five $(63 \%)$ of these patients. Response to vasospasm treatment was associated with a favorable clinical outcome $(\mathrm{p}<0.001$, Fisher's exact test; Table 2). 


\begin{tabular}{|c|c|c|c|}
\hline \multicolumn{4}{|c|}{$\begin{array}{c}\text { TABLE } 3 \\
\text { SUMMAR OF YASOSPASM TREATMENT IN } 125 \text { DISTAL ICA AND PROXMAL } \\
\text { MCA VESSEL SEGMENTS }\end{array}$} \\
\hline & \multicolumn{3}{|c|}{ No. of Vessed Segments Treated } \\
\hline & Iribal Treatm ent & Repeated Treatm ent & Crossover Treabnent \\
\hline $\begin{array}{l}\text { papaverine infusion } \\
\text { balloon angioplasty }\end{array}$ & $\begin{array}{r}24 \\
101\end{array}$ & $\begin{array}{c}10(42 \%) \\
1(1 \%)\end{array}$ & $\begin{array}{l}7(29 \%)^{\dagger} \\
0(0 \%) f\end{array}$ \\
\hline \multicolumn{4}{|c|}{$\begin{array}{l}\text { "Cinical response to wasospasm treatment assodiated with favorable clinical outcome } \\
(p \times 0.001 \text {, Fisher's exact test). } \\
\dagger \text { Crossover treatment to balloon angioplasty. } \\
\ddagger \text { Crossover treatment to papaierine infusion. }\end{array}$} \\
\hline
\end{tabular}

\section{Evaluation of CBF by SPECT}

Both pre- and posttreatment SPECT evaluations obtained within 24 hours of treatment were available for assessing a total of 58 anterior circulation vessel territories in 37 patients (Table 4). Prior to treatment, patients in the papaverine-treated group demonstrated decreased SPECT perfusion in 14 vessel segment territories $(88 \%)$. This was similar to the balloon angioplasty group in which $86 \%$ of vessel segment territories were decreased before treatment. Following treatment, five vessel segment territories (31\%) showed improvement within 24 hours after papaverine infusion, whereas 30 vessel segment territories (71\%) improved after balloon angioplasty. This difference was statistically significant $(\mathrm{p}=0.007$, Fisher's exact test).

\begin{tabular}{|c|c|c|}
\hline EYALUATION OF CBF BV SPECT & $\begin{array}{l}\text { TABLE } 4 \\
24 \text { HOURS FOLLOWI } \\
\text { LATION YASOSPASM }\end{array}$ & REATMENT OF ANTERIOR \\
\hline Variatle & $\begin{array}{c}\text { Papaverine Inf usi on } \\
\text { (13 pati ents) }\end{array}$ & $\begin{array}{c}\text { Ball oon Angioplasty } \\
\text { (24 patients] }\end{array}$ \\
\hline $\begin{array}{l}\text { Pretreatment perfusion } \\
\text { decre ased } \\
\text { normal }\end{array}$ & $\begin{array}{r}14(88 \%) \\
2(13 \%)\end{array}$ & $\begin{array}{l}36(86 \%) \\
6(14 \%)\end{array}$ \\
\hline $\begin{array}{l}\text { change in pertusion posttre atment } \\
\text { worsened } \\
\text { unchanged } \\
\text { im pro ved } \\
\text { total territories treated }\end{array}$ & $\begin{array}{r}4(25 \%) \\
7(44 \%) \\
5(31 \%) \\
16 \\
\end{array}$ & $\begin{array}{r}7(17 \%) \\
5(12 \%) \\
30(71 \%) \\
42\end{array}$ \\
\hline
\end{tabular}

\section{DISCUSSION}

The purpose of this study was to determine if balloon angioplasty was superior to papaverine infusion for the permanent reversal of anterior circulation vasosospasm following aneurysmal SAH. Transcranial Doppler sonography was used to compare and sequentially monitor the effect of each treatment on vessel caliber. Balloon angioplasty proved to be superior to papaverine infusion in producing the sustained reduction of elevated blood flow velocities associated with vasospasm to normal levels. Balloon angioplasty was also associated with fewer treatment failures than papaverine infusion.

\section{TCD Response to Treatment}

Before accepting the results of this study, it is useful to review the value and limitations of TCD 
sonography in detecting and monitoring vasospasm. Well-suited for the noninvasive detection of vasospasm,[35] TCD monitoring is not only technically feasible in the vast majority of cases but it is also directed toward the proximal basal vessel segments where vasospasm occurs.[37] In some cases, vasospasm may be limited to distal vascular distributions and can be missed by TCD examination.[37] Vasospastic MCAs, as visualized by angiography, consistently demonstrate flow velocities greater than $120 \mathrm{~cm} /$ second, with velocity being inversely related to arterial diameter.[1,2,13] Although angiographic responses to balloon angioplasty[8,9,15,36,47] and papaverine infusion[7,9,18] have both been reported to be successful, these observations have been predominantly made immediately following treatment. In this study, the use of TCD evaluation allowed daily monitoring throughout the intensive care unit stay as well as frequent examinations throughout the postoperative period. This monitoring protocol allowed comparison between treatment efficacy of balloon angioplasty and papaverine infusion on vessel caliber. Balloon angioplasty has been reported to be successful when used either soon after the onset of neurological deficit or in a delayed fashion.[4] It has been suggested that papaverine is most effective when used soon after the onset of vasospasm before arteries lose their ability to return to their normal caliber.[18] Because it is impractical to repeat angiography at frequent intervals, daily TCD evaluation following treatment offers an ideal approach to the monitoring of the posttreatment interval in which recurrent elevation of flow velocities is most often associated with the recurrent vasospasm that can adversely affect outcome.[17,21]

In the present study, balloon angioplasty resulted in immediate and permanent decrease of TCD-measured flow velocity and reversal of vasospasm in affected ICA and MCA segments (Fig. 3). Papaverine infusion also resulted in an initial decrease of TCD-measured velocities; however, reversal of vasospasm was transient in the majority of cases, rendering it much less effective as a treatment for vasospasm when used alone. Only one vessel segment initially treated with balloon angioplasty required repeated treatment, whereas $42 \%$ of vessel segments initially treated with papaverine required repeated infusion and $29 \%$ required subsequent balloon angioplasty. 


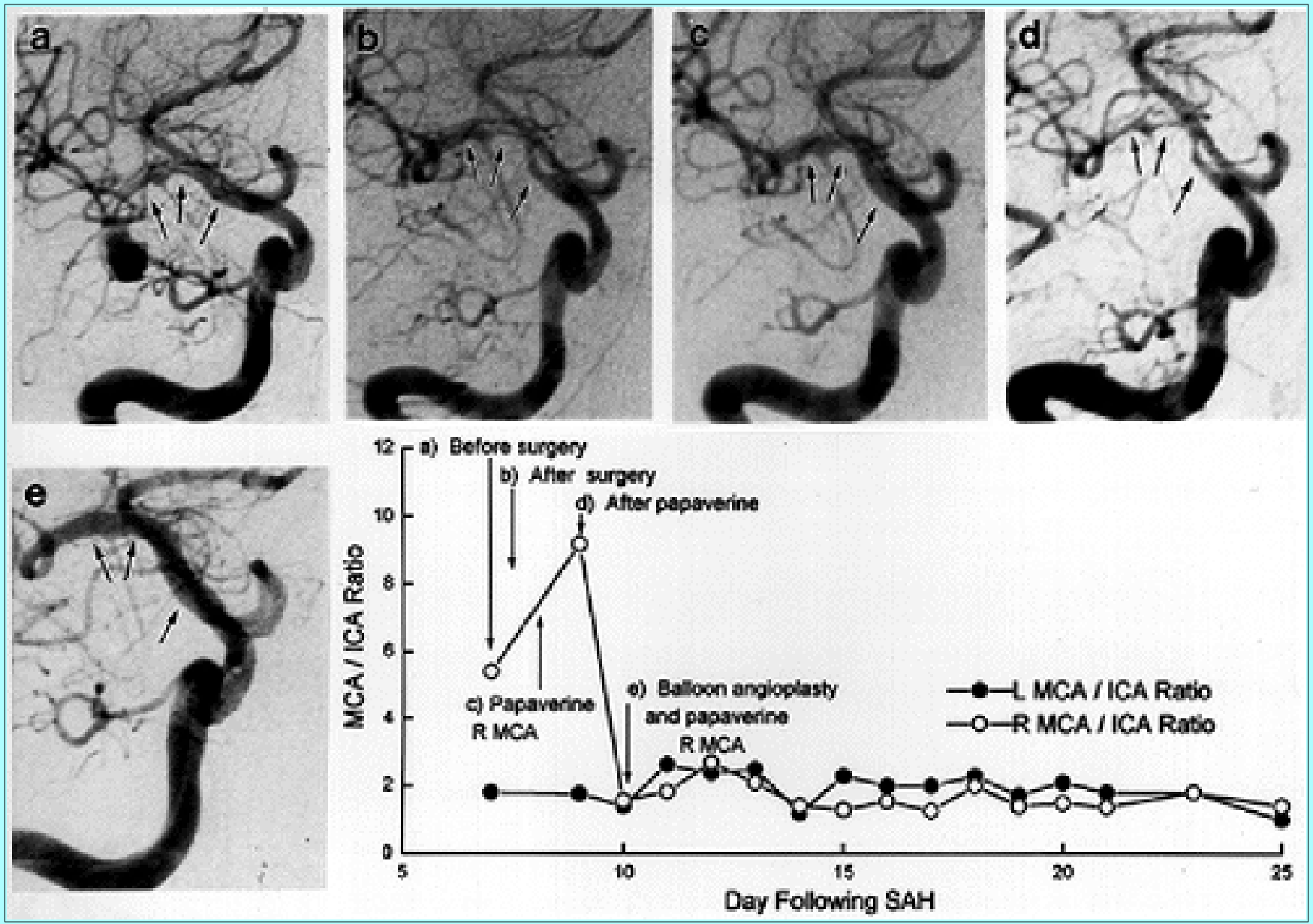

Fig. 3. Correlation of angiographically confirmed vasospasm with MCA/extracranial ICA velocity ratio in a representative case of a 47-year-old woman who suffered a Grade II SAH from a MCA aneurysm and in whom severe vasospasm was documented at the time of presentation. a: Initial angiogram obtained at presentation showing an unclipped MCA aneurysm and severe vasospasm of the MCA trunk (arrows). b: Angiogram obtained immediately after surgery illustrating aneurysm obliteration and persistent vasospasm of the MCA (arrows). c: Angiogram obtained immediately following papaverine infusion showing improved caliber of the MCA (arrows). d: Middle cerebral artery velocity and ratio, higher than preoperative values the day following papaverine treatment, prompted a repeated angiogram that shows recurrent severe vasospasm of the MCA (arrows). e: Angiogram obtained following balloon angioplasty and papaverine treatment illustrating increased diameter at the MCA (arrows), which correlated with a persistently decreased MCA/extracranial ICA velocity ratio, indicating sustained reversal of vasospasm.

\section{Why is Balloon Angioplasty Superior to Papaverine Infusion?}

In the majority of cases we found that balloon angioplasty provided permanent TCD-confirmed reversal of vasospasm after a single treatment, whereas the effects of papaverine were often transient, requiring multiple treatments. Such multiple treatments increase the potential for complications as well as cost associated with papaverine when used alone as a therapeutic strategy.

Although the reasons for the more sustained effect of balloon angioplasty treatment are not yet known, there is increasing evidence that anatomical and physiological mechanisms of action may be involved. Stretched and torn collagen fibers,[45] endothelial denudation and rupturing of the internal elastic 
lamina, $[6,10,41]$ thinning of the tunica media, $[6,16]$ and alteration of smooth-muscle cells[6] have all been associated with permanent reversal of vasospasm in a variety of models. In addition, impaired vasoreactivity to a wide range of vasoconstrictors has been observed following balloon angioplasty.[6] There is mounting evidence that vasospasm results from calcium-mediated smooth-muscle contraction during an early active phase and may be subsequently sustained by noncontractile processes.[12] It is possible that impairment of the vasoreactivity of smooth muscle may contribute to the early phase of persistent dilation following balloon angioplasty and that structural changes may account for its long-term efficacy.

The transient effects of papaverine infusion may be largely due to its action as a nonspecific smooth-muscle relaxant. The use of papaverine has been limited by both dose and mode of delivery. Although repeated infusions of intrathecal papaverine can reverse angiographically demonstrated vasospasm, $[22,40]$ this treatment is limited by its attendant elevated rates of morbidity. Preliminary studies of a sustained-release papaverine preparation have been reported.[14] Although the use of intraarterial papaverine in combination with other agents such as sodium nitroprusside or adenosine has been reported,[34] vasospasm was reversible only if treated within 2 days of SAH. Thus, it is likely that papaverine is most useful only when administered soon after SAH; unfortunately, in the clinical setting this may precede the time during which vasospasm becomes medically refractory.

\section{Role of Papaverine}

Although we found papaverine infusion alone to be less effective than balloon angioplasty for the treatment of vasospasm, a small initial infusion often facilitated access for balloon angioplasty procedures. Whereas the use of papaverine must be tempered by its attendant risk of hemodynamic complications, [33] it remains potentially useful for the treatment of vasospastic vessel segments which cannot be treated with balloon dilation, such as the anterior cerebral artery, MCA branches, and distal distributions. Further studies in which serial blood flow measurements are made are needed to establish papaverine's long-term effect in these vessels.

\section{Complications of Treatment}

The complications of balloon angioplasty and papaverine infusion should be considered in conjunction with their efficacy. With experience and attention to several caveats, the complications associated with balloon angioplasty can be minimized. It is important to obliterate the ruptured aneurysm before performing balloon angioplasty on a feeding vessel to prevent aneurysm rebleeding.[9] Therefore, when patients present with an unsecured aneurysm and symptomatic vasospasm, one treatment option is to proceed emergently with aneurysm obliteration followed by immediate balloon angioplasty.[27] Vessel rupture is another serious complication of balloon angioplasty,[30] occurring when the balloon is overdistended or positioned too distal in a vessel.[9] Balloon angioplasty therefore remains safest when limited to proximal vessel segments.

Papaverine infusion for the treatment of cerebral vasospasm might seem more attractive based on arguments that papaverine is safer because its infusion is less technically demanding than balloon angioplasty. This assumption, however, may not be true. Reported complications of papaverine infusion include monocular blindness, [7] brainstem dysfunction (including respiratory arrest),[5,31] focal neurological deficits that resolved on cessation of papaverine infusion, [18,19] and formation of crystal emboli.[32] Moreover, as the present study indicates, papaverine infusion does not provide permanent reversal of vasospasm, thus requiring repeated infusions with the associated risks of repeated 
angiography. We have previously reported that significant elevations in blood pressure and intracranial pressure, often accompanied by a decrease in cerebral perfusion pressure, were common complications of papaverine infusion not normally found with balloon angioplasty procedures. [33] When papaverine is required, it is therefore our policy to intubate the patient and use slow infusions with both arterial and intracranial pressure monitoring.

\section{Evaluation of CBF Changes by SPECT}

Single-photon emission computerized tomography scanning is one of several methods available used to evaluate rCBF in patients with vasospasm following SAH.[44] In poor-grade patients it can be difficult or impossible to discern whether vasospasm is accompanied by a worsened neurological condition despite maximum medical treatment.[9] We have found 99m-HMPAO SPECT scanning of the brain to be a useful adjunct to TCD and neurological examinations in deciding when to perform angioplasty in this situation. Additionally, SPECT scanning has proven to be of interest in assessing changes in relative CBF following treatment with balloon angioplasty[29] and papaverine infusion.[28]

In the present study, an improved relative CBF, assessed by SPECT scans at 24 hours following treatment of vasospasm, was observed with balloon angioplasty significantly more often than with papaverine infusion; $71 \%$ of vessel segment territories demonstrated improved CBF at 24 hours following balloon angioplasty, whereas only $31 \%$ of vessel segment territories showed improvement following papaverine infusion. Unfortunately, few studies were available for analysis of results at 48 hours or more following treatment. These results are consistent with our TCD observations that balloon angioplasty is superior to papaverine infusion when used alone for the treatment of vasospasm.

Although SPECT scanning assesses only relative CBF, Yonas, et al.,[46] made absolute CBF measurements using Xe-CT CBF evaluation and documented decreased CBF specific to territories supplied by vasospastic vessels. Nine of 14 patients who were persistently symptomatic despite maximum medical treatment demonstrated a CBF below $15 \mathrm{ml} / 100 \mathrm{~g} /$ minute in two or more adjacent 2 -cm cortical regions in the affected territory. Eight of these nine patients ultimately developed infarcts. No patient whose CBF remained above $18 \mathrm{ml} / 100 \mathrm{~g} /$ minute developed an infarct secondary to vasospasm. Used in combination with routine TCD detection of vasospasm, Xe-CT CBF or SPECT evaluation may prove valuable in deciding not only which patients will ultimately benefit from balloon angioplasty but may also help predict when earlier intervention during the asymptomatic period might be beneficial. Additionally, CBF imaging techniques such as Xe-CT and SPECT assess tissue perfusion, complementing the assessment of vessel diameter provided by TCD evaluation.

\section{CONCLUSIONS}

Transcranial Doppler sonography was used to compare the efficacy of balloon angioplasty with papaverine infusion in the permanent reversal of anterior circulation vasosospasm following aneurysmal $\mathrm{SAH}$. We conclude that balloon angioplasty is superior to papaverine infusion in providing permanent reversal of vasospasm.

\section{Acknowledgments}

We thank Paul Schwartz and Janet Schukar for their assistance in preparing photographic materials.

\section{References}


1. Aaslid R, Huber P, Nornes H: Evaluation of cerebrovascular spasm with transcranial Doppler ultrasound. J Neurosurg 60:37-41, 1984

2. Aaslid R, Markwalder TM, Nornes H: Noninvasive transcranial Doppler ultrasound recording of flow velocity in basal cerebral arteries. J Neurosurg 57:769-774, 1982

3. Adams RJ, Nichols FT, Hess DC: Normal values and physiological variables, in Newell DW, Aaslid R (eds): Transcranial Doppler. New York: Raven Press, 1992, pp 41-48

4. Barnwell SL, Higashida RT, Halbach VV, et al: Transluminal angioplasty of intracerebral vessels for cerebral arterial spasm: reversal of neurological deficits after delayed treatment. Neurosurgery 25:424-429, 1989

5. Barr JD, Mathis JM, Horton JA: Transient severe brain stem depression during intraarterial papaverine infusion for cerebral vasospasm. AJNR 15:719-723, 1994

6. Chan PDS, Findlay JM, Vollrath B, et al: Pharmacological and morphological effects of in vitro transluminal balloon angioplasty on normal and vasospastic canine basilar arteries. J Neurosurg 83:522-530, 1995

7. Clouston JE, Numaguchi Y, Zoarski GH, et al: Intraarterial papaverine infusion for cerebral vasospasm after subarachnoid hemorrhage. AJNR 16:27-38, 1995

8. Eskridge JM, Newell DW, Pendleton GA: Transluminal angioplasty for treatment of vasospasm. Neurosurg Clin North Am 1:387-399, 1990

9. Eskridge JM, Newell DW, Winn HR: Endovascular treatment of vasospasm. Neurosurg Clin North Am 5:437-447, 1994

10. Fujii Y, Takahashi A, Ezura M, et al: Balloon angioplasty immediately after surgical clipping for symptomatic vasospasm on admission. Report of four cases. Neurosurg Rev 18:79-84, 1995

11. Fujioka KA, Douville CM: Anatomy and freehand examination techniques, in Newell DW, Aaslid R (eds): Transcranial Doppler. New York: Raven Press, 1992, pp 9-32

12. Harada T, Seto M, Sasaki Y, et al: The time course of myosin light-chain phosphorylation in blood-induced vasospasm. Neurosurgery 36:1178-1183, 1995

13. Harders AG, Gilsbach JM: Time course of blood velocity changes related to vasospasm in the circle of Willis measured by transcranial Doppler ultrasound. J Neurosurg 66:718-728, 1987

14. Heffez DS, Leong KW: Sustained release of papaverine for the treatment of cerebral vasospasm: in vitro evaluation of release kinetics and biological activity. J Neurosurg 77:783-787, 1992

15. Higashida RT, Halbach VV, Cahan LD, et al: Transluminal angioplasty for treatment of intracranial arterial vasospasm. J Neurosurg 71:648-653, 1989

16. Honma Y, Fujiwara T, Irie K, et al: Morphological changes in human cerebral arteries after percutaneous transluminal angioplasty for vasospasm caused by subarachnoid hemorrhage.

Neurosurgery 36:1073-1081, 1995 
17. Hurst RW, Schnee C, Raps EC, et al: Role of transcranial Doppler in neuroradiological treatment of intracranial vasospasm. Stroke 24:299-303, 1993

18. Kaku Y, Yonekawa Y, Tsukahara T, et al: Superselective intra-arterial infusion of papaverine for the treatment of cerebral vasospasm after subarachnoid hemorrhage. J Neurosurg 77:842-847, 1992

19. Kassell NF, Helm G, Simmons N, et al: Treatment of cerebral vasospasm with intra-arterial papaverine. J Neurosurg 77:848-852, 1992

20. Kassell NF, Torner JC, Haley EC Jr, et al: The International Cooperative Study on the Timing of Aneurysm Surgery. Part 1: Overall management results. J Neurosurg 73:18-36, 1990

21. King WA, Martin NA: Critical care of patients with subarachnoid hemorrhage. Neurosurg Clin North Am 5:767-787, 1994

22. Kuwayama A, Zervas NT, Shintani, A, et al: Papaverine hydrochloride and experimental hemorrhagic cerebral arterial spasm. Stroke 3:27-33, 1972

23. Le Roux PD, Dailey AT, Newell DW, et al: Emergent aneurysm clipping without angiography in the moribund patient with intracerebral hemorrhage: the use of infusion computed tomography scans. Neurosurgery 33:189-197, 1993

24. Le Roux PD, Elliott JP, Downey L, et al: Improved outcome after rupture of anterior circulation aneurysms: a retrospective 10-year review of 224 good-grade patients. J Neurosurg 83:394-402, 1995

25. LeRoux PD, Elliott JP, Grady MS, et al: Anterior circulation aneurysms: improvement in outcome in good-grade patients 1983-1993. Clin Neurosurg 41:325-333, 1994

26. Le Roux PD, Elliott JP, Newell DW, et al: Predicting outcome in poor-grade patients with subarachnoid hemorrhage: a retrospective review of 159 aggressively managed cases. J Neurosurg 85:39-49, 1996

27. Le Roux PD, Newell DW, Eskridge J, et al: Severe symptomatic vasospasm: the role of immediate postoperative angioplasty. J Neurosurg 80:224-229, 1994

28. Lewis DH, Eskridge JM, McAuliffe W, et al: Effect of intra-arterial papaverine on cerebral blood flow in vasospasm after subarachnoid hemorrhage: a study using single-photon emission computed tomography. J Stroke Cerebrovasc Dis 5:24-28, 1995

29. Lewis DH, Eskridge JM, Newell DW, et al: Brain SPECT and the effect of cerebral angioplasty in delayed ischemia due to vasospasm. J Nucl Med 33:1789-1796, 1992

30. Linskey ME, Horton JA, Rao GR, et al: Fatal rupture of the intracranial carotid artery during transluminal angioplasty for vasospasm induced by subarachnoid hemorrhage. Case report. J Neurosurg 74:985-990, 1991

31. Mathis JM, DeNardo A, Jensen ME, et al: Transient neurologic events associated with intraarterial papaverine infusion for subarachnoid hemorrhage-induced vasospasm. AJNR 15:1671-1674, 1994

32. Mathis JM, DeNardo AJ, Thibault L, et al: In vitro evaluation of papaverine hydrochloride incompatibilities: a simulation of intraarterial infusion for cerebral vasospasm. AJNR 15:1665-1670, 
33. McAuliffe W, Townsend M, Eskridge JM, et al: Intracranial pressure changes induced during papaverine infusion for treatment of vasospasm. J Neurosurg 83:430-434, 1995

34. Nakagomi T, Kassell NF, Hongo K, et al: Pharmacological reversibility of experimental cerebral vasospasm. Neurosurgery 27:582-586, 1990

35. Newell DW: Transcranial Doppler ultrasonography. Neurosurg Clin North Am 5:619-631, 1994

36. Newell DW, Eskridge JM, Mayberg MR, et al: Angioplasty for the treatment of symptomatic vasospasm following subarachnoid hemorrhage. J Neurosurg 71:654-660, 1989

37. Newell DW, Grady MS, Eskridge JM, et al: Distribution of angiographic vasospasm after subarachnoid hemorrhage: implications for diagnosis by transcranial Doppler ultrasonography. Neurosurgery 27:574-577, 1990

38. Newell DW, LeRoux PD, Dacey RG Jr, et al: CT infusion scanning for the detection of cerebral aneurysms. J Neurosurg 71:175-179, 1989

39. Newell DW, Winn HR: Transcranial Doppler in cerebral vasospasm. Neurosurg Clin North Am 1:319-328, 1990

40. Ogata M, Marshall BM: Observations on the effects of intrathecal papaverine in experimental vasospasm. J Neurosurg 38:20-25, 1973

41. Ohkawa M, Fujiwara N, Tanabe M, et al: Cerebral vasospastic vessels: histologic changes after percutaneous transluminal angioplasty. Radiology 198:179-184, 1996

42. Pickard JD, Murray GD, Illingworth R, et al: Effect of oral nimodipine in reducing cerebral infarction and poor outcome after subarachnoid haemorrhage: British aneurysm nimodipine trial. Br Med J 298:636-642, 1989

43. Solomon RA, Fink ME, Lennihan L: Early aneurysm surgery and prophylactic hypervolemic hypertensive therapy for the treatment of aneurysmal subarachnoid hemorrhage. Neurosurgery 23:699-704, 1988

44. Soucy JP, McNamara D, Mohr J, et al: Evaluation of vasospasm secondary to subarachnoid hemorrhage with technetium-99m-hexamethyl-propypyleneamine oxime (HM-PAO) tomoscintigraphy. J Nucl Med 31:972-977, 1990

45. Yamamoto Y, Smith RR, Bernanke DH: Mechanism of action of balloon angioplasty in cerebral vasospasm. Neurosurgery 30:1-6, 1992

46. Yonas H, Sekhar L, Johnson DW, et al: Determination of irreversible ischemia by xenon-enhanced computed tomographic monitoring of cerebral blood flow in patients with symptomatic vasospasm.

Neurosurgery 24:368-372, 1989

47. Zubkov YN, Nikiforov BM, Shustin VA: Balloon catheter technique for dilatation of constricted cerebral arteries after aneurysmal SAH. Acta Neurochir 70:65-79, 1984 
Manuscript received April 17, 1997.

Accepted in final form September 17, 1997.

Address reprint requests to: David W. Newell, M.D., Department of Neurological Surgery, University of Washington, 325 Ninth Avenue, Seattle, Washington 98104.

Address for Dr. Le Roux: New York University, New York, New York.

This work was supported through Clinician Investigator Development Award No. 1K08 NS 01596901 to Dr. Newell, and also by National Institutes of Neurologiccal Disorders and Stroke training grant No. T 32 NS07144 to Dr. Elliott. 